\title{
AS DIFERENTES FORMAS DE RECONHECER IDENTIDADES CULTURAIS E SUA RELAÇÃO COM O DIREITO AO DESENVOLVIMENTO
}

\author{
Guilherme Miraldi da Silva Santos ${ }^{154}$
}

Recebido em: 17/11/2017

Aprovado em: 26/12/2017

\begin{abstract}
RESUMO
Busca-se estudar e questionar, no presente trabalho, a forma atual em que se apresentam os principais desafios filosóficos relativos ao reconhecimento de identidades culturais na atualidade; não somente, apresentar uma análise sistêmica dos conflitos apresentados neste processo de reconhecimento e as respectivas possibilidades de propostas oferecidas por instituições e acadêmicos para o desenvolvimento desta área. Procura-se descrever e questionar também suas múltiplas consequências no universo jurídico, político, econômico, cultural, social etc. Compõe-se, como forma principal de estudo as demandas e os conflitos entre valores e princípios no processo de reconhecimento de identidades culturais sociais. Ademais, observa-se a composição legislativa e social sobre as interfaces culturais e as práticas pertinentes a esta área com as suas respectivas consequências. Além disto, utiliza-se de crítica acadêmica para entender o porquê das dificuldades de superar os entraves desta demanda.
\end{abstract}

Palavras-chave: Reconhecimento. Identidade Cultural. Direito ao Desenvolvimento. Formas. Harmonia.

\section{INTRODUÇÃO}

A problemática do presente artigo define-se pelo estudo da tensão relativa ao processo de reconhecimento de identidades culturais. Sendo assim, busca-se identificar os pontos de tensão ou equilíbrio neste processo observando as consequências políticas, jurídicas, sociais, culturais, entre outros. Ademais, exemplifica as respostas múltiplas dadas por instituições e juristas para composição desta tensão visando a busca de harmonia política, jurídica e social.

\footnotetext{
${ }^{154}$ Mestrando do programa de pós-graduação em Direito (PPGD) da Universidade Veiga de Almeida, UVA. Advogado.
} 
A relevância ou importância desta pesquisa se dá pela falta de conhecimentos adequados sobre o assunto, principalmente em relação aos novos conflitos e vertentes acadêmicas sobre o tema. A análise adequada de questões referentes ao tema pode elucidar possibilidades de composição (no plano filosófico, político e jurídico) de linhas de efetivação de reconhecimento de identidades culturais, principalmente no que tange ao uso coerente da tolerância.

Ademais, busca-se a interdisciplinaridade entre o tema pesquisado e outras áreas do conhecimento frisando as concepções filosóficas e culturais que permitem trazer respostas às demandas de reconhecimento de identidades de grupos.

Há de se fazer as seguintes perguntas referentes ao tema: como seria possível reconhecer, de forma concomitante, grupos com identidades culturais distintas e conflitantes? Quais versões seriam preconceituosas? Como se dá o problema na prática? As soluções clássicas para o problema são suficientes ou coerentes? Quais os limites plausíveis de tolerância a uma determinada cultura?

A pesquisa tem caráter exploratório. O texto resultante da pesquisa se propõe a dar conta das questões relativas ao assunto estudado. Ademais há o foco sobre a possibilidade de as fontes de pesquisa abordarem os temas e responderem adequadamente a problemática de forma totalmente satisfatória.

Desta forma, primeiramente há o objetivo de identificar o Direito ao Desenvolvimento como um ramo do direito sine qua non para o processo de reconhecimento de identidades culturais e efetivação das demandas específicas de grupos sociais.

Posteriormente há o estudo do autor Yürgen Habermas da obra "multiculturalism

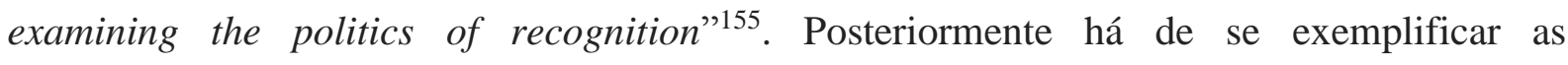
peculiaridades de características culturais as quais merecem o devido respeito e estudos, como por exemplo o Brasil na visão do autor Alberto Torres. Por fim há o detalhamento de movimentos culturais ou sociais que juridicamente e politicamente tem conseguido dar passos importantíssimos no processo de respeito/tolerância de reconhecimento de identidades culturais e imposições de políticas culturais, como por exemplo o movimento funk no Brasil.

Por fim se detalha a consequência jurídica e política destes processos de reconhecimento de identidades culturais. Quais processos seriam desnecessários ou injustos com exemplificação de consequências paradoxais de fins de procedimentos indevidos. Ademais, a necessidade de frisar que o reconhecimento de identidades culturais deve ser feito

\footnotetext{
${ }^{155}$ Multiculturalismo, examinando as políticas de reconhecimento.
} 
com coerência e harmonia com o Direito ao Desenvolvimento com ponderações de valores e análise dos melhores custos-benefícios das políticas públicas.

\section{METODOLOGIA}

Quanto aos fins, esta pesquisa será descritiva e explicativa. Descritiva porque buscará analisar como se forma os principais conflitos no processo de reconhecimento de identidades culturais no Brasil e no mundo. Explicativa porque intentará esclarecer os motivos os quais dificultam a superação dos principais entraves desta demanda na sociedade.

Visa assim descrever a forma atual em que o processo de reconhecimento se apresenta no campo jurídico, político, cultural, etc. Ademais, o trabalho será explicativo com base em autores clássicos de amplas áreas do saber que contribuam ou enriqueçam o entendimento dos pontos a serem estudados.

Quanto aos meios, a pesquisa será bibliográfica e documental. Bibliográfica, porque a fundamentação teórico-metodológica da pesquisa terá por base Códigos, obras de doutrinadores do Direito e obras de cunho psicológico, sociológico e antropológico, indispensáveis para entender o tema. Documental, porque será fundamentada em publicações de revistas, jornais, em documentos eletrônicos.

As fontes desta pesquisa serão as obras de doutrina do Direito, os Códigos e leis, assim como obras que tratem do objeto da pesquisa sobre uma abordagem sociológica, psicológica e antropológica. Utilizar-se-á na pesquisa, artigos em redes eletrônicas, documentos e matérias publicadas em revistas e jornais.

Os dados serão coletados em fontes bibliográficas, sites acadêmicos. Interpretados com redação própria serão os conteúdos doutrinários e a legislação utilizadas, contudo utilizando-se de transcrições, quando for necessário, para que não seja alterado o sentido dado pelo autor.

\section{ABORDAGEM TEÓRICA}

O Direito ao Desenvolvimento é um ramo do Direito que aborda o ser humano em facetas múltiplas. De forma variada lida, por exemplo, com garantias e fomentos para a defesa da integridade física e psicológica; o reconhecimento às identidades culturais; a capacidade de 
ampliação da educação formal; o acesso ao poder judiciário; o incremento das economias; a participação política local, nacional e global, etc.

Destarte, o Direito ao Desenvolvimento integra uma análise profunda e íntima dos fatores sociais que determinam ou auxiliam a capacidade de integridade e incremento dos modos de vida mais variados no mundo. Direito este que influencia em demasia sobre a qualidade da existência humana, pois, além de defender preceitos básicos, possibilita a afirmação de toda pessoa para que, se beneficiando com as garantias, possa exercer bem seus direitos. Prerrogativas e objetivos que dão dignidade para a existência em inúmeros planos.

Neste âmbito, podemos exemplificar que o cidadão ou grupos sociais não somente tenham liberdade de expressão, mas também bases para divulgar seus pensamentos, poder falar bem e defender seu modo de vida de forma saudável; não apenas direito a ingressar com ação judicial, mas também compreensão básica para o entendimento do funcionamento do judiciário em seu país e condições isonômicas para enfrentar um litígio judicial; não somente tenha direito à educação formal, mas também a uma educação que fale sobre a sua cultura, seus modos de vida, seus problemas específicos e também aborde pesquisas que tenham como conteúdo e objetivos resolver questões que lhe aflijam; não somente liberdade para ir e vir, mas também bons lugares para poder exercer suas demandas etc.

Inúmeras organizações nacionais e internacionais, de cunho governamental ou não, empenham-se neste propósito. Nestas finalidades há uma pressão natural da sociedade para que alguns princípios e objetivos sejam respeitados. E embora exista uma pauta de demandas relativamente pacificadas pelos mais diversos setores da sociedade, há uma discussão extremamente controversa sobre os meios de se efetivar o Direito ao Desenvolvimento. Por exemplo, deve-se fazer redistribuição de renda, contudo, das inúmeras formas de fazer tal redistribuição de renda, qual seria a mais eficiente, justa e harmônica com a sociedade? Todos devem ter Direito à moradia, entretanto, qual tipo de moradia caberia a cada um? Qual localização teria? Quem arcaria com seus custos? Teria que ser uma moradia com características arquitetônicas e urbanísticas coerentes com a cultura local ou com a cultura do habitante? Haveria isenção de tributos para hipossuficientes? etc. Desses exemplos, um merece destaque, sendo objeto urgente de pesquisa acadêmica pelas dificuldades no mundo jurídico-político e filosófico, ademais também pelas demandas múltiplas que determinam no plano real, indefinições, inseguranças e muitos conflitos. Esta dificuldade no Direito ao Desenvolvimento se dá no reconhecimento de identidades culturais.

O filósofo Jürgen Habermas nos traz esta problemática em seu artigo "Lutas por reconhecimento no Estado Constitucional Democrático”. Nele expõe (HABERMAS, 1994: 
107-148) que a Constituição coloca em vigor precisamente os direitos que os indivíduos devem conceder-se mutuamente no desejo de viver socialmente em harmonia. Legitimada por meio de direito positivo, esta concepção pressupõe a noção dos direitos individuais (subjetivos) e as pessoas coletivas individuais como portadoras de direitos. Nessa busca de reconhecimento há de proteger concomitantemente tanto os vulneráveis como os indivíduos e as pessoas coletivas.

No entanto, é feita uma pergunta retórica de grande valor: poderia a teoria do direito que é imaginada de forma individualista lidar adequadamente com as lutas por reconhecimento, em que se busca afirmação de identidades coletivas?

Primeiramente, é importante salientar que uma Constituição pode ser pensada como um projeto histórico que cada geração de cidadãos continua, de formas variadas, a perseguir. E por mais que se pense e se analise o Direito sobre um prisma individualista, há no mundo real uma arena política em que se encontram atores coletivos em disputa sobre metas coletivas e a distribuição de bens coletivos. Neste cenário é somente no discurso legal e nas salas de tribunais que os direitos são de fato afirmados. Sendo assim, as normas devem ser interpretadas em novas formas em diferentes contextos, levando em conta novas necessidades e interesses. Nesta luta sobre a interpretação e a satisfação de reivindicações históricas se faz uma luta pelos direitos legítimos em que os atores coletivos estão mais uma vez envolvidos, combatendo a falta de respeito pela sua dignidade.

As conquistas políticas do liberalismo e da socialdemocracia se fizeram como um produto da emancipação da "burguesia" e do movimento operário europeu. Sendo assim, estas dinâmicas de criação e imposição política e jurídica sugerem uma resposta afirmativa à pergunta da capacidade vigente de o Direito lidar adequadamente com as questões das identidades culturais. Sendo assim, é necessário superar a privação de direitos dos grupos mais desfavorecidos e com ela a divisão da sociedade em classes sociais.

No entanto, com o advento da reforma social liberal, esta luta pelo reconhecimento e igualdade de oportunidades sociais tomou forma de um tipo de busca pela universalização socioassistencialista de direitos civis. Isto não basta, é necessário que haja também direito à participação social e política com oportunidade de viver com expectativa real de segurança, dignidade e justiça social, respeitando as peculiaridades culturais na sociedade. Por exemplo, uma distribuição de bens coletivos nas sociedades capitalistas seria uma maneira de compensação sobre a desigualdade de condições de vida. Entretanto, além disto, é necessário saber de antemão que o reconhecimento de identidades culturais coletivas e a igualdade de direitos para formas culturais são questões diferentes. Enquanto o primeiro está ligado 
juridicamente ao seu respeito e consideração dentro da sociedade a segunda tem foco no pensamento jurídico da isonomia e na capacidade de incentivar os modos de vida de uma forma saudável. Ambos os fatores têm tangibilidade com o Direito ao Desenvolvimento.

Nestes grupos sociais podemos citar o feminismo, minorias nas sociedades multiculturais, povos que lutam por independência nacional, culturas artísticas menosprezadas e perseguidas etc. Todos estes grupos precisam de lutas para se afirmar dentro da sociedade e exercerem seu modo de vida de forma respeitosa e harmônica. Há inúmeras formas culturais de vida e tradições que têm sido marginalizadas, seja no contexto de uma cultura majoritária, numa sociedade global eurocêntrica, seja no contexto de perseguições religiosas, radicalismos de múltiplas formas etc.

Primeiramente é necessário exigir garantias de status e de sobrevivência para as identidades culturais. A este respeito Habermas afirma que à liberdade e às garantias para as identidades culturais poderia chamar de um sistema "liberal", mutatis mutandis. Neste sentido esta nova compreensão jurídica parece fazer uma profunda reforma na filosofia do Direito e no mundo político e jurídico contemporâneo, pois supõe, de plano, inúmeras e imensas alterações, de plano, nas sociedades e nas relações internacionais.

Há de se respeitar as identidades singulares de cada indivíduo e de seus grupos, independentemente de sexo, raça, etnia, ou qualquer modo cultural. Alguns grupos parecem já serem reconhecidos como grupos que precisam de proteção como, por exemplo, mulheres, homossexuais, indígenas, afro-americanos, judeus, Croatas na Sérvia, entre outros. Entretanto, o número de grupos que precisam de reconhecimento e proteção vai muito além destes grupos já reconhecidos pelo senso comum.

O mais importante, do ponto de vista habermasiano, é que a luta pelo reconhecimento não visa, na realidade, tanto a equalização das condições de vida. Isto é algo que vai de encontro ao Direito ao Desenvolvimento no qual o crescimento econômico não é o fator único ou principal na harmonia do exercício dos modos de vida, tampouco a equalização das características sociais, econômicas e culturais. De fato, paradoxalmente, parece este respeito pela dignidade humana, cultural e social apontar para o contrário, resultado disto são condições variadas de modos de vida. Desta forma, protegendo a integridade das tradições e formas de vida que os membros de grupos discriminados podem ser reconhecidos, ou seja, no plano de suas diferenças múltiplas.

Alguns problemas surgem com a demanda de reconhecimento como interferência indevida ou lesão à isonomia. Algo que precisa ser analisado caso a caso com bom senso e 
prática de ponderação de princípios constitucionais e valores consolidados pelo Direito Internacional.

Normalmente, por óbvio, o fracasso do reconhecimento cultural está ligado a uma bruta discriminação social. No caso do Brasil, é necessário um olhar acurado e capaz de perceber a complexidade de fatores que estão em jogo, influenciando contradições e desrespeitos hercúleos, tanto em uma visão macro de identidade cultural como por uma visão micro dos fatores que merecem reconhecimento e valorização.

No Brasil há a contradição de desrespeito dos valores e da cultura nacional pelos próprios brasileiros, o que torna a resolução extremamente difícil. Desde a criação do Estado nacional até os dias atuais ainda se obtém um sentimento de que o país é um local periférico (em contraste com países centrais da Europa ocidental e dos Estados Unidos da América), algo que traz consequências diversas, tais como a aceitação de posição subalterna em relações internacionais, um sentimento generalizado de exílio ou degredo, mesmo estando em sua terra natal, o repúdio a cultura local etc.

Para exemplificar esta visão podemos citar um escritor nacionalista que fora crítico ferrenho da desvalorização dos valores culturais nacionais e sua correspondente alienação no mundo jurídico, em especial da Constituição Federal da época, de 1891, que não trazia soluções e organização para as peculiaridades, valores e necessidades do Brasil. Alberto Torres, em “A organização nacional”, obra publicada em 1914, denunciava que a jurisprudência constitucional brasileira era um mimetismo da constituição norte americana, tal como defendia, com razão, que o direito privado nacional era uma imitação das doutrinas e jurisprudências portuguesa e francesa. Desta forma, acreditava ser a Constituição Federal a principal responsável pela desorganização do Brasil, algo que tange indubitavelmente o desenvolvimento nacional e abordaria as mesmas dificuldades que o Direito ao Desenvolvimento atual também enfrenta. Para ele, o povo brasileiro seria um povo honesto, inteligente, nobre, hospitaleiro, trabalhador... o país tinha vocação agrícola e era necessário combater a expropriação das riquezas nacionais pelo capital estrangeiro, contudo, para isto seria necessário observar as peculiaridades das características e cultura nacionais. Segundo Alberto Torres:

Nosso espírito não assimilou ainda a noção do papel político dos diversos membros da União e dos outros poderes públicos, essência da constituição, nos países onde a constituição é a expressão, o leito e o reflexo da vida nacional, o espelho do seu desenvolvimento, como na Inglaterra e nos Estados Unidos: noção que permitiu ao primeiro desses países realizarem uma vida legal e harmônica, com uma constituição feita de textos esparsos e de costumes e tradições: textos cujo sentido vai evoluindo com a marcha da sociedade, e costumes e tradições que se transformam, adaptam-se, 
E segue:

substituem-se, caducam e reaparecem, sem que os intérpretes vejam nisso conflito ou infração da lei, guiados pelo senso superior que faz da política, isto é, da arte de fazer o acordo das leis com a vida da sociedade (TORRES, 1982:2).

\begin{abstract}
(a constituição) é uma predicação política feita para assinalar que é uma lei adaptada à realidade social, obedecendo a fins práticos, não só originariamente inspirada em certa ordem de objetos gerais e permanentes, mas ordinariamente dominada pelo escopo de sua aplicação ao desenvolvimento evolutivo da sociedade (TORRES, 1982:3)
\end{abstract}

Alberto Torres se escandaliza (TORRES, 1982:14) com algumas posturas totalmente antinacionalistas e discriminatórias, exemplifica o fato de os governos se emprenharem em instalar colonos estrangeiros, dando-lhes propriedades e instrumentos de trabalho, ao passo que abandonavam à ociosidade não poucos milhões de compatrícios.

É surpreendente saber que esta discussão, há mais de um século, continua extremamente atual. Como paralelo, temos na atualidade, ano de 2016, o ingresso em massa de médicos cubanos para exercício da profissão no Brasil, enquanto o desemprego nacional atinge dezenas de milhões de brasileiros. Algo que gera um sentimento exacerbado de revolta em muitos cidadãos, embora também haja inúmeros brasileiros que defendem fervorosamente tal medida e pensam ser positivo para o desenvolvimento do país.

Os problemas dos modelos defendidos no Direito ao Desenvolvimento são múltiplos, segundo o doutor em Direito Internacional Welber Barral (BARRAL, 2005:149) o modelo etnocêntrico de desenvolvimento culminou em fracasso durante as últimas décadas. Entre algumas críticas pode-se citar o uso de países ocidentais como base para entendimento de "desenvolvimento", no entanto se esquece das experiências peculiares das diversas partes do mundo. Não somente, ignora cataclismas históricos em que a decadência de grandes civilizações demonstra que o desenvolvimento não é um continuum. Também afirma que há (ilogicamente) o pressuposto de que a experiência ocidental possa ser repetida em sociedades completamente distintas. Ademais, minimiza problemas como a falta de conhecimentos em regiões em desenvolvimento e também a impossibilidade ambiental fática de haver uma sociedade de consumo de massa em todo planeta. Por isso, é necessário sempre haver o cuidado de analisar se o modelo de desenvolvimento utilizado pode ser considerado "etnocêntrico", "míope" ou "ingênuo".

Voltando ao pensamento Habermasiano, há a defesa de que o Direito positivo pode exercer uma ferramenta de imenso valor para as lutas pelo reconhecimento. E isto parece de fato ser uma tendência mundial. 
Para exemplificar uma bruta discriminação social pode-se citar o estilo funk. Embora muitos digam que funk não é cultura; que seria um "lixo" da sociedade; que não deveria ser exercido em espaços públicos ou mesmo ser respeitada pelos órgãos governamentais e jamais fomentado pela sociedade; há de se citar o Direito positivo trazendo respaldo para o reconhecimento de uma identidade cultural.

Segundo a lei do Governo Estadual do Rio de Janeiro 5543/2009 o funk é um movimento cultural e musical de caráter popular:

\section{LEI No 5543, DE 22 DE SETEMBRO DE 2009. O GOVERNADOR DO ESTADO DO RIO DE JANEIRO}

Faço saber que a Assembleia Legislativa do Estado do Rio de Janeiro decreta e eu sanciono a seguinte Lei:

Art. $1^{\circ}$ Fica definido que o funk é um movimento cultural e musical de caráter popular.

Parágrafo Único. Não se enquadram na regra prevista neste artigo conteúdos que façam apologia ao crime.

Art. $2^{\circ}$ Compete ao poder público assegurar a esse movimento a realização de suas manifestações próprias, como festas, bailes, reuniões, sem quaisquer regras discriminatórias e nem diferentes das que regem outras manifestações da mesma natureza.

Art. $3^{\circ}$ Os assuntos relativos ao funk deverão, prioritariamente, ser tratados pelos órgãos do Estado relacionados à cultura.

Art. $4^{\circ}$ Fica proibido qualquer tipo de discriminação ou preconceito, seja de natureza social, racial, cultural ou administrativa contra o movimento funk ou seus integrantes.

Art. $5^{\circ}$ Os artistas do funk são agentes da cultura popular, e como tal, devem ter seus direitos respeitados.

Art. $6^{\circ}$ Esta Lei entra em vigor na data de sua publicação.

Rio de Janeiro, 22 de setembro de 2009.

\section{SERGIO CABRAL}

\section{Governador}

(ALERJ.Disponível em:

<http://alerjln1.alerj.rj.gov.br/contlei.nsf/f25571cac4a61011032564fe0052c89c/78ae

3b67ef30f23a8325763a00621702?OpenDocument> Acesso em 23/03/2016

Desta forma a lei traz uma prerrogativa: não há mais discussão se o funk é ou não um movimento cultural. De fato, legalmente, o é. Todavia, há de se salientar que há ressalvas para a consideração de uma identidade e movimento cultural, no caso estudado não se enquadram na regra prevista na lei conteúdos que façam apologia ao crime. Neste caso apenas esta ressalva deveria ser observada. Frases como "o funk não é cultura pois denigre as mulheres", "O funk estimula a sexualidade precoce nas crianças", "o funk incentiva a violência”, etc, não teriam mais força alguma para invalidar o funk como identidade e movimento cultural.

No mesmo sentido, sobre os desafios para o processo de implementação de políticas culturais no Brasil, Lia Calabre afirma que: 
Uma política cultural atualizada deve reconhecer a existência da diversidade de públicos, com as visões $\mathrm{e}$ interesses diferenciados que compõem a contemporaneidade. No caso brasileiro temos a premência de reverter o processo de exclusão, da maior parcela do público, das oportunidades de consumo e de criações culturais. Nestor Canclini utiliza o conceito de hibridização cultural como uma ferramenta para demolir a concepção do mundo da cultura em três camadas: culta, popular e massiva. O conceito de hibridização abrange diversas mesclas interculturais, não apenas as raciais, que se costuma encaixar no termo mestiçagem, ou as preponderantemente religiosas, categorizadas enquanto sincretismos. (CALABRE, 2007:99)

Outro aspecto importantíssimo nas lutas por reconhecimento é a conscientização da população para as necessidades e demandas de grupos sociais. Neste âmbito, pode-se exemplificar campanhas como a "\#elesporelas" (eles por elas) da OAB/RJ. Nela há uma dedicação junto à iniciativa da ONU: mulheres a convidar os advogados a se conscientizarem e se comprometerem a lutar contra o machismo na sociedade. $\mathrm{O}$ foco central do movimento é o entendimento de que esse assunto não é exclusivamente feminino e a parceria com homens e meninos é fundamental.

Nesta luta feminista há a conscientização de inúmeros atos machistas ou discriminatórios como, por exemplo, a falta de similaridade de remuneração de homens e mulheres para as mesmas funções trabalhistas; o assédio sexual banalizado na sociedade contra as mulheres e meninas; o preconceito contra a mulher na política etc.

Um ponto de grande importância é a compreensão de que na discriminação existe interseccionalidade de fatores:

É comum que se veja hoje nas redes outra palavra relacionada ao tema, a
interseccionalidade. E, para Roberta, o conceito se relaciona desde a sua origem com
o Direito: "A interseccionalidade surge na literatura feminista negra na década de
1980 nos Estados Unidos com Kimberley Crenshaw, que era advogada. Crenshaw
viu que a separação de políticas para mulheres, para negros, para pobres,
representava algo que não se alinhava à realidade porque essas opressões na prática
se atravessavam. Eram, portanto, interseccionais". Ela continua: "trabalhar uma
política somente direcionada à mulher, não atendendo as particularidades que uma
negra vivenciava na sociedade não trazia os benefícios que se esperava para as
políticas públicas. (BITTAR, 2007:11)

Ademais, é necessário frisar que os fomentos a grupos culturais devem ser feitos com políticas que procurem fazer com que identidades possam ser reconhecidas e respeitadas.

De acordo com Habermas, o objetivo das políticas liberais foi destacar a aquisição da qualidade de gênero e para garantir às mulheres igualdade de oportunidades para competir por empregos, posição social, educação, poder político, e assim por diante, independentemente dos resultados. Mas a igualdade formal, que foi parcialmente atingida assim, só fez o tratamento desigual, de fato, das mulheres ainda mais evidente. Desta forma, é necessário, indiscutivelmente, ações que possam trazer respeito real a esta identidade. 
Entretanto, as intervenções por estas buscas não podem fazer com que os grupos sociais não tenham capacidade de fazer mudanças em suas vidas, ou seja, que as identidades sejam enrijecidas a ponto de tirar a liberdade dos cidadãos. Esta característica fica patente na busca pela proteção das culturas indígenas, na qual muitas vezes se faz um "museu humano" em que há isolamento de grupos sociais e penalização das garantias pelas mudanças naturais que ocorrem na existência de uma sociedade. Ademais é necessário estar atento a uma possível "normalização" de atos discriminatórios ou injustos pelo fato de haver uma compensação para estes fatos negativos na sociedade. Não somente, atos que sejam paliativos e dificultem mudanças realmente significativas. Ademais, estas ações não podem ser paternalistas ou mesmo reafirmar estereótipos do senso comum, e por fim, jamais atuar de forma violenta ou radical, o que infelizmente muitas vezes acaba ocorrendo nas relações sociais.

Esta política vai ao encontro da declaração sobre o Direito ao Desenvolvimento, adotada pela Resolução n 41/128 da Assembleia Geral das Nações Unidas. Em seu artigo 2º parágrafo $3^{\circ}$ no qual determina que:

Art. $2^{\circ} \S 3$. Os Estados têm o Direito e o dever de formular políticas nacionais adequadas para o desenvolvimento, que visem ao constante aprimoramento do bem-estar de toda população e de todos os indivíduos, com base em sua participação ativa, livre e significativa, e no desenvolvimento e na distribuição equitativa dos benefícios daí resultantes. (Sem grifos no original) ${ }^{156}$

De fato, é indiscutível que cada forma de reconhecimento tem suas particularidades e peculiaridades. Pode-se citar o exemplo do feminismo em que se difere dos reconhecimentos de outros grupos sociais os quais são designados como "minorias". No caso da luta pelo reconhecimento do movimento feminista é necessário entender que se trata da maioria da população. Desta forma, se faz necessário políticas que tratem com profundidade dos problemas enfrentados de uma forma generalizada tanto em matéria de lugar como de público alvo. Diferente seria, por exemplo, de reconhecimento e de luta pelo respeito à cultura e religião judaica no Brasil. Seria infrutífero despender recursos para campanhas em áreas no país onde inexiste ou praticamente não há judeus. Desta forma, a luta pelo reconhecimento se faz pela interpretação coerente das necessidades reais, especificidades, interesses e buscas de realizações de cada grupo social.

${ }^{156}$ ONU, 1986. Disponível em: $<$ http://www.direitoshumanos.usp.br/index.php/Direito-aoDesenvolvimento/declaracao-sobre-o-direito-aodesenvolvimento.html>. Acesso em 23 de maio de 2016) 
Nessa construção, o Estado deve entender que as metas políticas não podem ser apenas as de cunho geral ou universal, mas também abarcar aquelas que abordem formas particulares de vida nos grupos sociais. Neste âmbito se encontram questões como os grupos sociais ou cidadãos se entendem dentro do Estado, por exemplo, como pertencentes a uma região específica, herdeiros de uma cultura particular ou com tradições que desejam perpetuar ou descontinuar ${ }^{157}$, como querem lidar com sua história, com a natureza etc. Contudo, cabe ao Estado proibir modos de vida cultural que transgridam os valores básicos e principais da sociedade, sendo assim uma interferência competente e possível, como a proibição do infanticídio em culturas indígenas, o funk que faça apologia ao crime, a religião que exija do crente a doação universal de seus bens para uma suposta salvação divina, o feminismo radical e agressivo etc.

Pacífico é o entendimento que é necessário ouvir as demandas de cada grupo, a participação no campo político é fundamental e o próprio processo de construção de reconhecimento com harmonia e legitimação se faz com a democracia respaldando o Estado de Direito como o Estado de Direito respaldando a democracia, uma vez que um fator não pode existir sem o outro.

Entretanto, inegavelmente há de se admitir que alguns casos detêm uma dificuldade pelas complexidades fáticas apresentadas. Isto fica patente em grupos sociais que buscam o reconhecimento e que reivindicam objetivos conflitantes. Nestes casos é necessário apresentar soluções que passem primeiramente pela tentativa incessante de composição de conflitos por meios de negociação e mediação. Indubitavelmente, o diálogo em um processo participativo tende a criar um ambiente que minimize ao máximo os conflitos e objetive a composição e a harmonização dos conflitos. Infelizmente muitas das soluções são apresentadas sem a consulta ou participação dos grupos em questão. No caso indígena, por exemplo, a própria Constituição Federal, talvez em parapraxia, admite os reais desejos da sociedade brasileira em relação à cultura indígena. No art $215 \S 1^{\circ}$, da Constituição Federal, o Estado garante proteger as manifestações populares, indígenas e afro-brasileiras, além de outras. Contudo, afirma que estas mesmas culturas são participantes do "processo civilizatório nacional". Ora, tais palavras geram uma enorme contradição nos próprios termos. $\mathrm{O}$ processo civilizatório é uma visão etnocêntrica da cultura desenvolvimentista humana, da visão com resquício positivista etc. Uma aspiração que, por si só, vai de encontro aos princípios e aos desejos de culturas que apenas desejam conservar suas cíclicas tradições.

${ }^{157} \mathrm{O}$ estado não pode garantir a sobrevivência de uma cultura, pois se assim o fizer estará roubando a liberdade de seus membros a possibilidade de preservar, mudar ou deixar determinado modo de vida. 
Neste sentido, o Art. $215 . \S^{\circ}$ prevê que :

O estado protegerá as manifestações das culturas populares, indígenas e afro-brasileiras, e das de outros grupos participantes do processo civilizatório nacional.

Por outro lado, é importante salientar que o desenvolvimento de culturas indígenas não pode sofrer preconceito baseado em suposta "perda" de cultura (como já fora exposto). Deste modo, um indígena que dirige um automóvel, que assiste à televisão, que utiliza roupas de marcas estrangeiras, pode, sem nenhum empecilho ou inconveniente, continuar sendo considerado indígena. Da mesma forma que, em um mundo globalizado, brasileiros comumente dirigem automóveis estrangeiros, assistem filmes estrangeiros e vestem roupas estrangeiras não deixam de ser considerados brasileiros, ou seja, esta premissa vale tanto para macro como para microculturas.

Sendo assim, se faz necessário que exista um reconhecimento com coerência e harmonia com o Direito ao Desenvolvimento, se fazendo necessário processos que tenham participação dos grupos em questão e respeito às suas particularidades, não somente, bem como ponderando-se valores e analisando os melhores custos-benefícios das políticas públicas.

\section{CONSIDERAÇÕES FINAIS}

O reconhecimento das identidades culturais múltiplas parece se encaminhar para um consenso no campo do Direito ao Desenvolvimento, entretanto, os modos de se reconhecer e fomentar no campo prático ainda é ponto extremamente controverso e não pacificado. Contudo, o presente trabalho acadêmico permitiu descrever que, embora muitos acreditem que o reconhecimento das culturas e grupos coletivos por si só já é válido e justo, não pode ser concebido como um ideário ou política coerente com os valores consolidados pelo estágio democrático e de direitos que a contemporaneidade apresenta. Sendo assim, para que haja reconhecimentos com coerência e harmonia com o Direito ao Desenvolvimento é necessário que estes processos sejam enfrentados com participação dos grupos em questão e respeito às suas particularidades, não somente, ponderando-se valores e analisando os melhores custosbenefícios das políticas públicas. 
Sendo assim, os fomentos e as criações normativas devem obedecer a diretriz de possibilitar, de modo efetivo, o fornecimento de direitos a grupos sociais que possam ser eficazes sem causar consideráveis danos ao próprio grupo ou a outros. Ou seja, que possam trazer benefícios do processo de reconhecimento de identidade culturais com o mínimo de efeitos negativos, estes que são inexoráveis no processo.

No plano da efetividade é necessário que os direitos reconhecidos não fiquem apenas no plano programático ou retórico mas sim com a eficácia necessária advinda de seu espírito filosófico, político e jurídico.

Entretanto, o paradoxal é que esta efetivação pode incorrer em prejuízos para outras linhas filosóficas, políticas e jurídicas que tangenciam o reconhecimento do mesmo grupo social identitário ou de outro grupo. Por exemplo, ao criar uma determinada reserva indígena de uma determinada tribo pode haver, concomitantemente, a demanda da criação de outra reserva indígena de outra tribo no mesmo local, criando assim tensões e conflitos e fazendo dilemas de que o reconhecimento de um grupo pode significar o não reconhecimento de outro e vice-versa, criando problemas éticos e jurídicos insolúveis para atender na totalidade todas as demandas em princípio justas. Além disto, uma mesma medida pode ser considerada discriminatória por uns ou positiva para outros. No caso da política afirmativa de cotas para negros em universidades há grupos de valorização da cultura negra que repudiam tais práticas por serem (supostamente) racistas, por outro lado, há outros grupos de valorização da cultura negra que congratulam tais políticas por (supostamente) combaterem a discriminação e a opressão sobre os negros.

A subjetividade dos valores culturais impõe a incapacidade científica de dar respostas peremptórias às demandas de fomentos e reconhecimento de grupos fazendo com que o próprio processo democrático e a legitimidade do consenso e composições permitam a dogmática jurídica pacificar, em termos, este processo conflituoso e tensional.

Da própria dubiedade da justiça advém as perguntas políticas mais inquietantes: quais nações ou grupos tem direito a determinadas terras? Sendo pacificado a necessidade de fazer redistribuição de renda, das inúmeras formas de fazê-la, qual seria a mais eficiente, justa e harmônica com a sociedade e grupos específicos? Se todos devem ter direito à moradia, qual tipo de moradia caberia a cada um? Qual localização teria? Quem arcaria com seus custos? Teria que ser uma moradia com características arquitetônicas e urbanísticas coerentes com a cultura local ou com a cultura do habitante? Haveria isenção de tributos para hipossuficientes construírem sua moradia? Como reconhecer identidades culturais de forma harmônica com o Direito ao desenvolvimento? 
A expansão do entendimento do liberalismo pela visão meramente individualista para social permite um aumento da autonomia de determinados grupos. Tira-se assim a marginalização de muitos. Todavia, quais seriam os limites desta liberdade? Pelo menos os valores consagrados constitucionalmente e no plano dos direitos humanos devem ser levados em consideração. Mesmo que seja um juízo de valor, estes são plausíveis com o processo democrático. Por exemplo, a pedofilia deve ser combatida com a maior intolerância (nem sempre o termo "intolerância" significa algo ruim) possível seja em qualquer grupo social ou cultural: NEM SEMPRE CULTURA SIGNIFICA ALGO BOM.

Ademais, há o problema de "normalização"158 de problemas sociais com medidas paliativas de promoções de direitos compensativos ou que atinjam pequena parte de indivíduos dentro de um grupo. Como por exemplo a criação de cotas para a universidade para alunos de escolas públicas e não políticas reais de enfrentamento aos problemas múltiplos estruturais da educação pública no país.

Outro problema ainda mais complexo é quando a própria política de reconhecimento e defesa de culturas se tornam, por si só, paradoxalmente, opressivas e intransigentes. Por exemplo, a defesa da cultura indígena não deve impedir os intercâmbios culturais e as mudanças naturais dentro da própria cultura. Um indígena que assiste à televisão não deixa de ser indígena por causa disso, tampouco um brasileiro que assiste a um filme norte-americano em um televisor de tecnologia japonesa fabricado na China deixa de ser brasileiro por causa disso.

Não somente, outro fator muito controverso e complexo é a impossibilidade de críticas a algum tipo de cultura ou postura. Há de salientar que é o próprio intercâmbio cultural de tecnologias, valores, posturas, artes etc que fazem a humanidade progredir. Nem sempre a crítica severa a um tipo de cultura pode ser visto como negativo, pois fora o fato de que a liberdade de expressão tende ora a combater posturas maléficas ora a reafirmar pensamentos inadequados, a crítica a uma cultura pode ser construtiva ou mesmo "mexer com os brios" de algum grupo, por exemplo, é totalmente vergonhoso que o povo brasileiro tenha se acostumado a viver sem saneamento básico e assista inerte aos sucessivos processos eleitorais sem demandar pela superação da falta deste item mais imprescindível. Caracterizando assim nada menos que subdesenvolvimento humano. Por outro lado, é importante frisar que o desmerecimento de uma cultura ou nação, como denunciado por Alberto Torres referente à cultura e ao povo brasileiro, de fato deve ser combatido e repudiado. A "condenação"

\footnotetext{
158 Tornar normal, banal, admissível.
} 
perpétua dos brasileiros como seres de segunda categoria, indubitavelmente, além de ser uma ignorância é um ato imoral, repulsivo e hediondo. Filosoficamente, não menor que o preconceito de nazistas sobre judeus de que estes seriam seres de raça/espécie/etnia inferior. Embora a comparação pareça exagerada, são as permissões aos pequenos desrespeitos que criam ambiente para a estruturação de fenômenos de grandes preconceitos e opressões. O desmerecimento indevido é um processo de legitimação de abusos a serem cometidos.

Tornando ainda mais complexa a questão, os modelos defendidos no Direito ao Desenvolvimento são múltiplos e devem respeitar a caraterísticas específicas de cada cultura. Não se deve ignorar cataclismas históricos em que a decadência de grandes civilizações demonstra que o desenvolvimento não é um continuum. Também há (ilogicamente) o pressuposto de que a experiência ocidental possa ser repetida em sociedades completamente distintas. Ademais, minimiza-se problemas como a falta de conhecimentos em regiões em desenvolvimento e também a impossibilidade ambiental fática de haver uma sociedade de consumo de massa em todo planeta. Por isso, é necessário sempre haver o cuidado de analisar se o modelo de desenvolvimento utilizado pode ser considerado "etnocêntrico", "míope" ou "ingênuo".

Por fim, como as políticas de reconhecimento de identidades culturais devem ser impostas, o direito positivo, com suas limitações, é um grande aliado nestas buscas. Procedimento sine qua non na busca de respeito e harmonia entre grupos e povos.

\section{REFERÊNCIAS}

ALERJ. Lei $\quad \mathbf{n}^{\mathbf{0}} \quad \mathbf{5 5 4 3 ( 2 0 0 9 )}$ Disponível em: <http://alerjln1.alerj.rj.gov.br/contlei.nsf/f25571cac4a61011032564fe0052c89c/78ae3b67ef30 f23a8325763a00621702? OpenDocument> Acesso em 23/03/2016.

BARRAL, Welber. Revista sequência. Nº 50. P.143-168. Jul. 2005.

BITTAR, Cássia. Tribuna do advogado. № 556. Rio de Janeiro: OAB/RJ. 2016.

CALABRE, Lia. Políticas culturais no Brasil. EDUFBA. 2007.

HABERMAS, JÜRGEN. Multiculturalism examining the politics of recognition. New Jersey: Princeton University Press, 1994. p. 107-148. 
ONU. Assembleia Geral das Nações Unidas. Declaração sobre o Direito ao Desenvolvimento adotada pela resolução n⿳0041/128 (1986). Disponível em: <http://www.direitoshumanos.usp.br/index.php/Direito-ao-Desenvolvimento/declaracaosobre-o-direito-ao-desenvolvimento.html>. Acesso em 23 de maio de 2016

TORRES, Alberto. A Organização Nacional. 4. Ed. Brasília: UnB. 1982.

\title{
THE DIFFERENT WAYS TO RECOGNIZE CULTURAL IDENTITIES AND ITS RELATIONSHIP WITH THE RIGHT TO DEVELOPMENT
}

\begin{abstract}
In the present work, the present form in which the main philosophical challenges regarding the recognition of cultural identities in the present time are dealt with; Not only to cope with a systemic analysis of the conflicts which appear in this recognition process and the respective possibilities of proposals offered by institutions and scholars for the development of this area. The research seeks to describe and question its multiple consequences in the legal, political, economic, cultural, social, etc. universe. The main form of study is the demands and conflicts between values and principles in the process of recognition of social cultural identities. In addition, the legislative and cultural composition on the cultural interfaces and the practices pertinent to this area with their respective consequences are observed. Moreover, academic criticism is used to understand the reasons why it is being difficult overcoming the obstacles of this demand.
\end{abstract}

Keywords: Recognition. Cultural Identity. Right to Development. Scheme. Harmony. 